\title{
Autism, the current pathological trend in psychiatry
}

\author{
Humberto Nicolini
}

\begin{abstract}
Laboratorio de Enfermedades Psiquiátricas y Neurodegenerativas, Instituto Nacional de Medicina Genómica, Ciudad de México, México.
\end{abstract}

\section{Correspondence:}

Humberto Nicolini

Laboratorio de Enfermedades Psiquiátricas y Neurodegenerativas, Instituto Nacional de Medicina Genómica.

Periférico Sur 4809, Tlalpan, C.P. 14610, Ciudad de México, México.

Phone: +52 555350 - 1900 Ext.

1196

Email: hnicolini@inmegen.gob.mx

\section{Citation:}

Nicolini, H. Autism, the current pathological trend in psychiatry. Salud Mental, $41(3)$, 105-107. doi: 10.17711/SM.0185-3325.2018.022
In the past decade, autistic spectrum disorders (ASD) have received great attention from society, as well as funding for biomedical research. This has been reflected in the significant increase in scientific publications on the subject. It should be noted that in 2000 there were only approximately 500 publications in PubMed whereas there are currently over 40,000. Accordingly, autism has become one of the most representative conditions in neuroscientific development in current psychiatry. In recent years, novel results have been obtained in the identification of autism genes through various methodologies such as cytogenetic studies, allelic association, genome and exome screening, and epigenetics. The genetic architecture of autism is complex since hundreds of genes interact in its etiology, producing different effects on the phenotype. Despite progress in both the clinical aspect and research on animal models, it is not easy to establish a diagnosis in everyday clinical practice, except for certain causes of syndromic autism secondary to fragile- $X$ syndrome or Rett syndrome, among other variants which it is already possible to diagnose (Muhle, Reed, Stratigos, \& Veenstra-VanderWeele, 2018). However, it is important to point out that this will not make a difference for the treatment, since there are no therapeutic recommendations based on the genotype. It should be noted that these mutations only account for a very low proportion of the total number of cases, and that unfortunately, in Mexico, there are no molecular epidemiology data. The accuracy of a genetic diagnosis may in some cases relieve relatives' uncertainty.

From the immunological perspective, active neuroinflammation with an increase in proinflammatory cytokines has been described, in both serum and the cerebrospinal fluid, which alters immuno-cellular functions (Onore, Careaga, \& Ashwood, 2012). In the Central Nervous System, microglia have an immunological component whose function is affected in patients with autism (Salter \& Stevens, 2017). However, it is unclear whether these alterations are the result of the aberrant changes undergone by a brain with autism (for example, in reaction to prenatal infections) (Lombardo et al., 2018), or whether they are contributory factors to this condition.

The study of affiliative behaviors has been the subject of considerable research work involving the vasopressin and oxytocin systems, resulting in the publication of several clinical trials (Anagnostou et al., 2012). Hormonal factors, specifically prenatal exposure to androgens, are being studied under the hypothesis that autism is the result of a hyper-masculinized brain that produces alterations in neuronal interconnectivity (Zeestraten et al., 2017).

Likewise, interesting theories on autism have emerged from a cognitive approach. For example, the "Theory of Mind" (which consists of understanding mental states in oneself and others) was applied to autism for the first time in 1985 and is currently key to understanding social communication (Baron-Cohen, Leslie, \& Frith, 1985). In this respect, various brain regions that participate in social perception and cognition, such as the medial prefrontal cortex, the temporo-parietal junction, the amygdale, and the fusiform gyrus, show hypo-functional activity in patients with autism (Philip et al., 2012).

At the same time, brain imaging and neurophysiology studies can predict the diagnosis of autism by recording evoked potentials using a specific paradigm (when children 
observe different faces) (Elsabbagh et al., 2015). The use of other techniques, such as white matter tractography and the analysis of its organization, has made it possible to predict the disease during the development of children between the ages of six and 24 months at risk of autism (Emerson et al., 2017).

Another cognitive theory is based on the discovery of mirror neurons (activated when a person observes someone else perform an action, as if, in their brain, they are prepared to imitate and experience the same feeling), and it is thought that in patients with autism, these neurons function inadequately (Hamilton et al., 2013). Some research work indicates that executive functions are those that are most severely affected in autism and that there are difficulties in processing information, as well as an abnormal pattern in brain connectivity with low, long-range interconnectivity from anterior to posterior regions. The prefrontal cortex and anterior cingulate constitute the critical node of disconnection underlying social difficulties in autism (Ajram et al., 2017).

The effect of non-genetic factors or those attributable to the environment in the causality of autism has been described in detail. Advanced paternal age is a consistent risk factor in many countries, which may suggest mutations in germ cells (Sandin et al., 2016). Chemical agents, medication, complications during pregnancy, and adverse factors during pregnancy have also been associated with autism (Gardener, Spiegelman, \& Buka, 2011). On the other hand, there is no evidence that the use of vaccines or antidepressants during gestation is a risk factor (DeStefano, Price, \& Weintraub, 2013; Brown, Hussain-Shamsy, Lunsky, Dennis, \& Vigod, 2017).

It is striking that autism does not carry the same burden of stigma as other mental illnesses such as schizophrenia or addictive disorders. I would venture to say that some people have even enjoyed receiving a diagnosis related to the autistic spectrum rather than another less fashionable mental illness. For this reason, there is some confusion in the social desire to belong to this group (ASD), which has resulted in cases such as Mexico, where legislators have suggested that autism is a choice (Diario Oficial de la Federación, 2015), meaning that it is considered a condition rather than an illness.

Recently, Baron-Cohen (2018), the author of the Theory of Mind, published a key article for the understanding of autism, in which he states that Hans Asperger colluded with the Nazis, and therefore that his name should not be honored with this condition.

At the same time, several academic and civil society associations have promoted the research and awareness of this disease. This is the case of AutismSpeaks, which has made significant contributions to the genetics of autism, and ICARE4Autism, led by doctor Joshua Wienstein, who visited Mexico in February 2017. The goals of these groups include increasing the visibility of these disorders among health authorities and society. Doctor María Elena Medina-Mora, Director of the Instituto Nacional de Psiquiatría Ramón de la Fuente Muñiz, has coordinated research activities and the training of professionals in autism care, as well as the dissemination of the actions of ICARE4Autism among the Mexican psychiatric community.

In September 2017, a psychiatric genetics congress was held at the Instituto Nacional de Medicina Genómica, where a symposium on recent advances in the topic of autism was presented, with the participation of doctor Thomas Schulzte, president of the International Society of Psychiatric Genetics. The Consorcio Mexicano del Autismo has been formalized, with the collaboration of five groups of professionals interested in researching various aspects of autism. Lastly, in March 2018, an agreement was established with other groups from Latin America, such as Colombia, Costa Rica and Panama, to create an autism network to collaborate and exchange knowledge with other Spanish-speaking countries.

\section{REFERENCES}

Ajram, L. A., Horder, J., Mendez, M. A., Galanopoulos, A., Brennan, L. P., Wichers, R. H., ... McAlonan, G. M. (2017). Shifting brain inhibitory balance and connectivity of the prefrontal cortex of adults with autism spectrum disorder. Translational Psychiatry, 7(5), e1137. doi: 10.1038/tp.2017.104

Anagnostou, E., Soorya, L., Chaplin, W., Bartz, J., Halpern, D., Wasserman, S., ... Hollander, E. (2012). Intranasal oxytocin versus placebo in the treatment of adults with autism spectrum disorders: a randomized controlled trial. Molecular Autism, 3(1), 16. doi: 10.1186/2040-2392-3-16

Baron-Cohen, S., Leslie, A. M., \& Frith, U. (1985). Does the autistic child have a "theory of mind"? Cognition, 21(1), 37-46.

Baron-Cohen S. (2018). The truth about Hans Asperger's Nazi collusion. Nature, 557(7705), 305-306. doi: 10.1038/d41586-018-05112-1

Brown, H. K., Hussain-Shamsy, N., Lunsky, Y., Dennis, C. E., \& Vigod, S. N. (2017). The Association between Antenatal Exposure to Selective Serotonin Reuptake Inhibitors and Autism: A Systematic Review and Meta-Analysis. The Journal of Clinical Psychiatry, 78(1), e48-e58. doi: 10.4088/JCP.15r10194

Diario Oficial de la Federación. (2015). Decreto por el que se expide la Ley General para la Atención y Protección a Personas con la Condición del Espectro Autista. Retrieved from http://www.dof.gob.mx/nota_detalle.php?codigo $=5390948 \&$ fecha $=30 / 04 / 2015$

DeStefano, F., Price, C. S., \& Weintraub, E. S. (2013). Increasing exposure to antibody-stimulating proteins and polysaccharides in vaccines is not associated with risk of autism. The Journal of Pediatrics, 163(2), 561-567. doi: 10.1016/j. jpeds.2013.02.001

Elsabbagh, M., Bruno, R., Wan, M. W., Charman, T., Johnson, M. H., Green, J., \& BASIS Team. (2015). Infant neural sensitivity to dynamic eye gaze is associated with later emerging autism. Infant neural sensitivity to dynamic eye gaze relates to quality of parent-infant interaction at 7-months in infants at risk for autism. Journal of Autism and Developmental Disorders, 45(2), 283-291. doi: 10.1007/ s10803-014-2192-9

Emerson, R. W., Adams, C., Nishino, T., Hazlett, H. C., Wolff, J. J., Zwaigenbaum, L., ... Kandala, S. (2017) Functional neuroimaging of high-risk 6-month-old infants predicts a diagnosis of autism at 24 months of age. Science translational medicine, 9(393), eaag2882. doi: 10.1126/scitranslmed.aag2882

Hamilton, A. F. D. C. (2013). Reflecting on the mirror neuron system in autism: a systematic review of current theories. Developmental cognitive neuroscience, 
3, 91-105.

Gardener, H., Spiegelman D., \& Buka, S. L. (2011). Perinatal and neonatal risk factors for autism: a comprehensive meta-analysis. Pediatrics, 128, 344-55.

Lombardo, M. V., Moon, H. M., Su, J., Palmer, T. D., Courchesne, E., \&Pramparo, T. (2018). Maternal immune activation dysregulation of the fetal brain transcriptome and relevance to the pathophysiology of autism spectrum disorder. Molecular Psychiatry, 23(4), 1001-1013. doi: 10.1038/mp.2017.15

Muhle, R. A., Reed, H. E., Stratigos, K. A., \& Veenstra-VanderWeele, J. (2018). The Emerging Clinical Neuroscience of Autism Spectrum Disorder: A Review. JAMA psychiatry, 75(5), 514-523. doi: 10.1001/jamapsychiatry.2017.4685

Onore, C., Careaga, M., \& Ashwood, P. (2012) The role of immune dysfunction in the pathophysiology of autism. Brain, Behavior, and Immunity, 26(3), 383-392.

Philip, R. C., Dauvermann, M. R., Whalley, H. C., Baynham, K., Lawrie, S. M.,
\& Stanfield, A. C. (2012). A systematic review and meta-analysis of the fMRI investigation of autism spectrum disorders. Neuroscience \& Biobehavioral Reviews, 36(2), 901-942.

Salter, M. W. \& Stevens, B. (2017). Microglia emerge as central players in brain disease. Nature medicine, 23(9), 1018-1027. doi: 10.1038/nm.4397

Sandin, S., Schendel, D., Magnusson, P., Hultman, C., Surén, P., Susser, E., \& Henning, M. (2016). Autism risk associated with parental age and with increasing difference in age between the parents. Mol Psychiatry. Molecular Psychiatry, 21(5), 693-700. doi: 10.1038/mp.2015.70

Zeestraten, E. A., Gudbrandsen, M. C., Daly, E., de Schotten, M. T., Catani, M., Dell'Acqua, F., ... Baron-Cohen, S. (2017). Sex differences in frontal lobe connectivity in adults with autism spectrum conditions. Translational Psychiatry, 7(4), e1090. doi: 10.1038/tp.2017.9 